\title{
The Measures Contribution Researches on Renewable Energy Accommodation Based on Production Simulation
}

\author{
MI Zhe ${ }^{1, *}$, ZHANG Jinfang ${ }^{1}$, and LIU Jun ${ }^{1}$ \\ ${ }^{1}$ State Grid Energy Research Institute Co., Ltd., Beijing 210003, China
}

\begin{abstract}
This paper presents the impacts of load, source and grid factors on renewable energy accommodation in the northern region of China. Renewable energy curtailment reasons and key measures to improve accommodations are also discussed. The production simulation method is utilized to analysis renewable energy accommodation and the Shapely value method is introduced to calculate the accommodation contribution rate of different factors. The result shows that the amount of renewable energy accommodation is $389 \mathrm{TWh}$ in northern region of China by the year 2020. The contribution rate of load, source and grid factors to renewable energy accommodation are $39 \%, 35.8 \%$ and $25.1 \%$, respectively.
\end{abstract}

\section{Introduction}

In recent years, China has experienced rapid development of renewable energy. Both renewable power installed capacity and renewable energy generation amount have increased rapidly. By the end of 2017, the grid-connected installed capacity of wind and solar power in China are more than $160 \mathrm{GW}$ and 130 $\mathrm{GW}$, respectively. China has ranked first in the world in both wind and solar power installed capacity. The development of renewable energy, represented by wind power and solar power, is an important measure to promote energy production and consumption revolution. The development of renewable energy is also the key measure to achieve the development goal of non-fossil energy accounts for $15 \%$ of the proportion of primary energy consumption in 2020.

The northern region of China is the main area for large-scale development of renewable energy, for its abundant reserves of wind and solar energy resource. Large scale wind power bases have been built in some northern regions, such as Jiuquan in Gansu and Hami in Xinjiang. Large scale solar power sites have also rapidly developed in Gansu and Qinghai province.

However, at the same time of continuous and rapid growth of renewable energy installed scale, the phenomena of wind and solar power curtailment still exist. which brings serious challenge to power. Although the renewable energy accommodation in 2017 is better than in the previous year, the renewable power curtailment rate is still high in some provinces of northern China. According to the information issued by National Energy Administration of China, in 2017, the whole country's wind power curtailment amount is about 42 TWh. Top two serious provinces are Gansu and Xinjiang, whose wind curtailment rates area both higher than $30 \%$. The total amount of solar power curtailment in China is 7.3 TWh. Gansu and Xinjiang are also the top two serious provinces, whose solar curtailment rates are both higher than $20 \%$.

Renewable energy accommodation is a systematic project, involving many aspects such as power generation, transmission, distribution, and consumption. To solve the problem of renewable energy curtailment, the power system should get balanced development in all "source-grid-load" aspects [1,2]. This paper tries to illustrate the impacts of source-grid-load factors on renewable energy accommodation. The contribution rates of different measures on renewable energy accommodation are analysed, according to scenario analysis based on production simulation. A numerical example analysis is also carried out to verify the analysis method.

\section{Analysis of Renewable Energy Curtailment Problems}

\subsection{Influence Factors of Renewable Energy Accommodation}

Renewable energy accommodation influenced by many factors such as system load level \& characteristic, power supply structure, system adjustment ability, grid transmission capability and output characteristics of renewable energy output power. Many factors are constantly changing and dynamic. For example, the output power of renewable energy is variable in different time and season; the adjustment capacity of combined heat and power (CHP) generator is different in heating or non-heating periods; the power load characteristics are also different in different days of a week or year. The amount of renewable energy accommodation is seasonal and time-varying. The renewable energy accommodation

\footnotetext{
* Corresponding author: mizhe@sgeri.sgcc.com.cn
} 
capability of northern China is higher in summer, lower in winter, higher in daytime and lower in nighttime.
Factors that influence renewable energy accommodation are showed in Fig. 1.

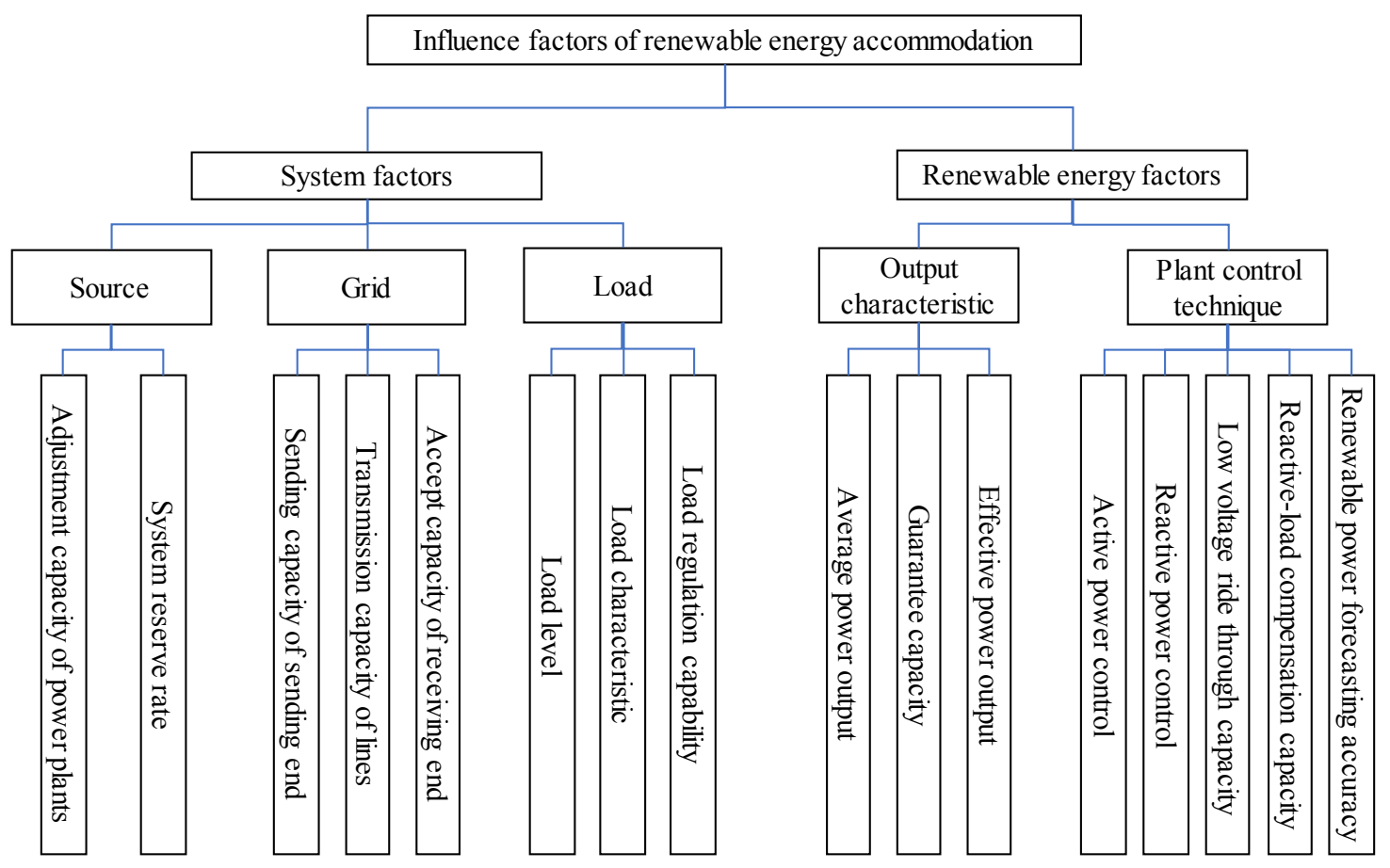

Fig. 1. Influence Factors of Renewable Energy Accommodation

\subsection{Analysis of Renewable Energy Curtailment}

In the aspect of power generation, the system operational flexibility is relatively low. The installed capacity ratio of coal-fire thermal power is significantly high in China. By the end of 2017, the cumulative installed capacity ratio of coal-fire power is $62 \%$ in the whole country, and particularly in northern region, this value is higher than $70 \%$. Meanwhile, the cumulative installed capacity ration of peak-shaving units, like pumped storage and gas-fire power, is only $6 \%$ in the whole country, and $4 \%$ in the northern region. The low peak-shaving capacity of thermal power plants in winter is a main cause of renewable energy curtailments.

In the aspect of power consumption, there is a significant mismatch between load and power generation in northern region of China. the proportion of installed wind \& solar power capacity in northern region is up to $65 \%$ of the total in China. In contrast, the electricity consumption of northern region accounts for only $35 \%$ of the whole country. Therefore, the renewable energy power generated in the northern region is difficult to accommodation all in the local region.

In the aspect of power transmission, the northern region power transmission capacity is generally inadequate. By the end of 2017, the installed wind \& solar power capacity in northern region is more than 190 $\mathrm{GW}$, while the power transmit capacity to the east and central regions is less than $40 \mathrm{GW}$, which accounts for only $20 \%$ of the installed capacity of renewable energy. In addition, the transmission lines from the northern to the east and central regions are also undertaking the transmission task of coal power.
Overall, the main factors that cause renewable energy curtailments in northern region of China are low winter peak-shaving capacity, insufficient local load demand and inadequate power transmission capacity.

\subsection{Key Measures for Improving Renewable Energy Accommodation}

In the aspect of power generation, thermo-electric decoupling modification of CHP plants should be speed up to improve their operational flexibility in winter. The minimum technical output of modified CHP units can be as low as $40 \sim 50 \%$ of their nominal rating. The improved peak-shaving capacity of CHP plant will effectively increase renewable energy accommodation space in winter [3].

In the aspect of power consumption, the scale of power load should be expanded. to enlarge renewable energy demand. On the one hand, the increase of power load level can enlarge renewable energy demand. On the other hand, demand side response should be widely implemented and promoted to improve the regulating ability of the power system from the load side [4].

In the aspect of power transmission, power transmission capacity should be effectively improved. More UHV transmission lines need to be planned and constructed according to the rapid growth of wind \& solar power generation capacity in northern region [5]. The transmission proportion of renewable energy in the existing lines is also need to be increased based on the construction of "Energy Internet". 


\section{Production Simulation Analysis of Renewable Energy Accommodation}

\subsection{Principle of Production Simulation}

Production simulation gives a comprehensive measure of renewable energy accommodation, by simulating power balances of very time point in the whole year. System operation conditions, such as load characteristics, generation unit start-up arrangements and transmission line operation modes, are all considered in the production simulation. At a certain moment, the renewable energy output power can be all accommodated when it is less than the system peak-shaving capability, while the excess part will be curtailed when it is greater the system peak-shaving capability. The curtailment energy is the integration of curtailed power to the time. The Curtailment Principle in production simulation is diagramed in Fig. 2.

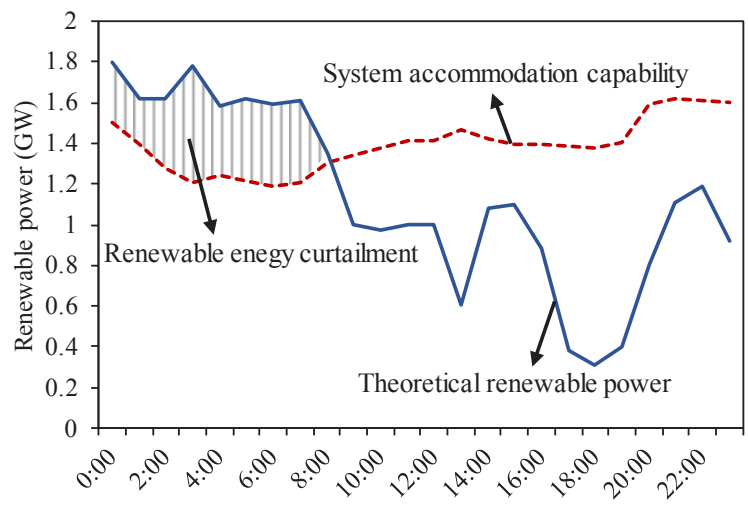

Fig. 2. Renewable Energy Curtailment Principle in Production Simulation.

The optimization target in the production simulation is to maximize the renewable energy accommodation in a certain period, and the objective function is as follows:

$\max \sum_{t=1}^{T}\left[C_{W} P_{W}(t)+C_{W} P_{W}(t)\right] \Delta t$

where, $C_{W} \& C_{S}$, installed capacity of wind and solar power; $P_{W}(t) \& P_{S}(t)$, wind and solar output power per unit capacity at moment $t ; \Delta t$, unit time interval.

Constraint of power balance:

$$
C_{G} P_{G}(t)+C_{W} P_{W}(t)+C_{S} P_{S}(t)+C_{T} P_{T}(t)=P_{L}(t)
$$

where, $C_{G}$, installed capacity of conventional power generation units; $P_{G}(t)$, output power of conventional power generation units per unit capacity at moment $t ; C_{T}$, capacity of transmission lines; $P_{T}(t)$, transmission power per unit transmission capacity at moment $t ; P_{L}(t)$, load power at moment $t$.

Constraint of peak-shaving capability:

$$
\left\{\begin{array}{c}
P_{G \cdot \min }(t) \leq P_{G}(t) \leq P_{G \cdot \max x}(t) \\
0 \leq P_{W}(t) \leq P_{W \cdot 0}(t) \\
0 \leq P_{S}(t) \leq P_{S \cdot 0}(t)
\end{array}\right.
$$

where, $P_{G \cdot \min }(t) \& P_{G \cdot \max }(t)$, the maximum and minimum technological output of conventional power generation units at moment $t ; P_{W \cdot 0}(t)$, theoretical output wind power at moment $t ; P_{S \cdot 0}(t)$, theoretical output solar power at moment $t$.

Constraint of transmission capability:

$P_{T \cdot \min }(t) \leq P_{T}(t) \leq P_{T \cdot \max }(t)$

where, $P_{T \cdot \min }(t) \& P_{T \cdot \max }(t)$, the maximum and minimum transmission power at moment $t$.

\subsection{Analysis of Measures Contribution}

The contribution of source, grid and load measures to renewable energy accommodation is investigate by calculating their Shapley values. The Shapley value method is a common method to solve multi-member cooperation problems [6,7], which reflects the contribution of an individual factor in a cooperation.

The calculation formula for Shapely value is as follows:

$X_{i}(V)=\Sigma_{S \in M_{i}} W(|s|) \cdot[V(S)-V(s /\{i\})]$

where,

$W(|S|)=[(m-|S|) !(|S|-1) !] / m !$

$X_{i}(V)$, the Shapely value of factor $i ; M_{i}$, all subsets containing factor $i$; $|S|$, the number of factors in subset $S$; $V(S)$, the benefit of subset $S ; V(S /\{i\})$, the benefit of the subset which forms by removing factor $i$ from $S$; $m$, the number of factors in the universal set.

The contribution in renewable energy accommodation of factor $i$ is calculated by the following formula:

$C_{T_{\mathrm{i}}}=X_{\mathrm{i}} / \Sigma_{\mathrm{i}}^{m} X_{\mathrm{i}}$

\section{Numerical Example}

\subsection{Scenario Design}

The numerical example is carried out for the whole northern China region under the planning year of 2020. The installed capacity of wind, solar, thermal and hydro power generation units of the region are 130, 100, 520 and $50 \mathrm{GW}$, respectively. The theoretical annual utilization hours of wind and solar power are 2000 and 1500 hours, respectively. Scenarios are designed based on the varieties of power load, thermal unit operational flexibility and grid transmission capacity.

Base Scenario: The load level, thermal unit operational flexibility and grid transmission capacity are all kept the level in 2017. The total electricity consumption is $2350 \mathrm{TWh}$. The averaged minimum technological output of thermal units is $70 \%$ of their nominal rating in winter. The grid transmission capacity is $35 \mathrm{GW}$. 
Planning Scenario: The scenario is designed according to the 13th "Five-year" Plan of electric power development. The total electricity consumption increases by $14 \%$ compared to 2017 . The averaged minimum technological output of thermal is improved to $65 \%$ of the nominal rating. The grid transmission capacity is doubled.

According to the execution of plans by 2020, 6 Transition Scenarios are also designed. 1) Only the load level grows; 2) Only the minimum technological output of thermal is improved; 3) Only grid transmission capacity is doubled; 4) Both load level and minimum technological output of thermal are improved; 5) Both load level and grid transmission capacity are increased; and 6) Both peak-shaving capacity of thermal units and transmission capacity of the grid are enhanced.

The main boundary conditions of each scenarios are shown in Table 1.

Table 1. Scenario Main Boundary Conditions

\begin{tabular}{cccc}
\hline Scenario & $\begin{array}{c}\text { Electricity } \\
\text { consumption } \\
(\mathrm{TWh})\end{array}$ & $\begin{array}{c}\text { Minimum CHP } \\
\text { output rate } \\
(\%)\end{array}$ & $\begin{array}{c}\text { Grid } \\
\text { transmission } \\
\text { capacity } \\
(\mathrm{GW})\end{array}$ \\
\hline Base & 2350 & 70 & 35 \\
Planning & 2680 & 65 & 70 \\
Transition 1 & 2680 & 70 & 35 \\
Transition 2 & 2350 & 65 & 35 \\
Transition 3 & 2350 & 70 & 70 \\
Transition 4 & 2680 & 65 & 35 \\
Transition 5 & 2680 & 70 & 70 \\
Transition 6 & 2350 & 65 & 70 \\
\hline
\end{tabular}

\subsection{Simulation Results and Factor Contribution Analysis}

The renewable energy accommodations in the above scenarios are calculated by the production simulation. In Base Scenario, the amount of renewable energy accommodation is $295.5 \mathrm{TWh}$, and the renewable energy curtailment of the whole system is $28 \%$. In Base Scenario, the amount of renewable energy accommodation is $295.5 \mathrm{TWh}$, and the renewable energy curtailment rate of the whole system is $28 \%$. In contrast, Planning Scenario shows a renewable energy accommodation amount of 389.5 TWh, and the renewable energy curtailment rate is $5 \%$. The simulation results of each scenario are listed in Table 2.

The contribution rate of source, grid and load factors are calculated by utilizing Shapley value method. Take load factor as an example, the Shapely value is calculated according to the following process. There are 4 scenarios that contains the load factor, which are \#1, \#4, \#5 and Planning Scenario, and their renewable energy accommodation amounts are 348.5, 382.5, 370.5 and 389 TWh, respectively. By removing the load factor from the 4 scenarios, another 4 scenarios are formed in turn, which are Base, \#2, \#3 and \#6 Scenario. The corresponding renewable energy accommodation amounts of these scenarios are 295.5, 344, 336 and 369, respectively. According to the formula (5) and (6), the Shapely value of load factor for renewable energy accommodation is $36.5 \mathrm{TWh}$. In the same way, the Shapley values of source and grid factors can also be calculated, which are 33.5 and $23.5 \mathrm{TWh}$, respectively. According to the formula (7), the contribution rate of load, source and grid factors are $39 \%, 35.8 \%$ and $25.1 \%$, respectively.

Table 2. Scenario Production Simulation Results

\begin{tabular}{ccc}
\hline Scenario & $\begin{array}{c}\text { Renewable energy } \\
\text { accommodation } \\
\text { amount (TWh) }\end{array}$ & $\begin{array}{c}\text { Renewable energy } \\
\text { curtailment rate } \\
\text { (\%) }\end{array}$ \\
\hline Base & 295.5 & 28 \\
Planning & 389 & 5 \\
Transition 1 & 348.5 & 15 \\
Transition 2 & 344 & 16 \\
Transition 3 & 336 & 18 \\
Transition 4 & 382.5 & 6 \\
Transition 5 & 370.5 & 9 \\
Transition 6 & 369 & 10 \\
\hline
\end{tabular}

\section{Conclusion}

This paper discusses the reasons of renewable energy curtailment and key measures to improve accommodations in the northern region of China. The main factors that cause renewable energy curtailments in northern region of China are low winter peak-shaving capacity, insufficient local load demand and inadequate power transmission capacity. The production simulation method is utilized to analysis the amount of renewable energy accommodation. Production simulation gives a comprehensive accommodation measure by simulating power balances of very time point in the whole year. The contribution of source, grid and load measures to renewable energy accommodation is judged and compared by investigate their Shapley values. The numerical example is carried out for the whole northern region of China under the planning year of 2020. The analysis result shows that the renewable energy accommodation amount is about 389 TWh by 2020 . The contribution rate of load, source and grid factors to renewable energy accommodation are 39\%, 35.8\% and $25.1 \%$, respectively.

\section{References}

1. Y. Shu, Z. Zhang, J. Guo, et al. Proceedings of the CSEE, 37(1), 1 (2017)

2. Z. Pei, C. Wang, Q. He, et al. Electric Power, 49(11), 1 (2016)

3. Z. Pei, X. Wang, C. Dong, et al. Power System Technology, 41(6), 1786 (2017)

4. H. Pei, D. Li, W. Han, et al. Power DSM, 18(6), 45 (2016) 
5. C. Gao, D. Niu, M. Ma, et al. Electric Power, 50(7), 56 (2017)

6. L. Li, Y. Ding, Z. Tan, et al. East China Electric Power, 37(11), 1803 (2009)

7. Z. Tan, Y. Song, H. Zhang, et al. Automation of Electric Power Systems, 37(23), 63 (2013) 